\title{
Users' perceptions of outpatient quality of care in Kilosa District Hospital in Central Tanzania
}

\author{
D. JUMA* and R. MANONGI \\ Kilimanjaro Christian Medical College, P.O. Box 2240, Moshi, Tanzania
}

\begin{abstract}
Use of users' perception in measuring quality of care has been shown to be useful in screening problems and in planning for improvement of quality of health care delivery. Traditionally, quality of care has been measured using professional standards, neglecting users' opinions which may leave psychosocial needs unattended. The objective of this descriptive cross-sectional study was to assess users' perceptions of quality of care given at outpatient department (OPD) at Kilosa District Hospital in Central Tanzania. Hospital based exit interviews were conducted to adult patients or caregivers of children attending the hospital. Focus Group Discussions were conducted among community members in selected villages within the hospital catchment area. Information on perceptions on care provider-patient interaction, cost of service, availability of medicines, equipment and health personnel was sought from the participants. Overall OPD was perceived to have several shortcomings including verbal abuse of patients by care providers, lack of responsiveness to patients' needs, delays, inadequate examination, unreliable supply of medicines, lack of confidentiality and favouritism in health care provision. Cost of service was perceived to be reasonable provided medicines were available. In conclusion, provider-patient interactions, timely services, supply of medicines and favouritism were the major factors affecting quality of service at the hospital. Efforts should be made to address the shortcomings so as to improve quality of care and users perceptions.
\end{abstract}

Key words: users' perceptions, health care, quality, hospital, Tanzania

\section{Introduction}

Quality of health care is the degree of performance in relation to a defined standard of interventions known to be safe and that have the capacity to improve health within available resources. It can also be defined as meeting the health needs at the lowest cost and within regulations (Øvretveit, 1992). Traditionally quality of health care has been measured using professional standards and neglecting the importance of patient perception (Haddad et al., 2000). Users' perceptions are now considered to be important source of information in screening for problems and developing an effective plan of action for quality improvement in health care organization (WHO, 2004). Documentation and use of users' perceptions, however, is still not given adequate emphasis in developing countries (Haddad et al., 2000). Client's perceptions of care directly influences his or her compliance with treatment and the continuity of patient-physician relationship and hence outcomes. It also influences utilization and readiness to contribute to financing health services (Akin \& Hatchnson, 1999; Leonard et al., 2002; Kamuzora \& Gilson, 2007).

Health service should be able to meet both medical and psychosocial needs. However, most often care provided is costly and substandard, and imposes a heavy financial burden on poor households (WHO, 2000). Sometimes patients' expectations are not met by professionals (Jung et al., 1997). Issues of concern to patients include care givers' interaction with patients, accessibility of health services, availability of drugs and equipment, and cleanness (Haddad et al, 1998, 2000; Baltussen \& Ye, 2006). Health services provision in Tanzania are constrained by a number of factors in terms of structure, process and outcome (Urassa et al., 2002; Manongi et al., 2006; Kamuzora \& Gilson, 2007).

Out-patient department (OPD) is the gateway to almost all of the hospital services. Globally, $80 \%$ of patients are attended at OPD (WHO, 2000). Similarly about $80 \%$ of patients in Tanzania hospitals are out-patients ( $\mathrm{MoH}, 2005)$. It follows that if quality of outpatients services are improved a large part of health services in the country would be appreciated by many. In

\footnotetext{
* Correspondence: E-mail: dajkay@gmail.com
} 
order to do that, it is important to establish and address factors which play a role in determining whether a patient's judgement of the health care received is positive or negative. This would help health care providers and hospital management to focus their changes on these factors and hence improve health care delivery. The objective of this study was to identify users' perceptions of quality of outpatient services at Kilosa District Hospital in Tanzania.

\section{Materials and Methods}

\section{Study area}

This study was carried out at the Kilosa District Hospital in Kilosa District, central Tanzania. Kilosa District $\left(6^{0} 49^{\prime} 60 S, 36^{0} 58^{\prime} 60 \mathrm{E}\right)$ has an area of $14,245 \mathrm{~km}^{2}$ and an estimated population of 542,442 of whom 108,488 are women of childbearing age (National Bureau of Statistics, 2003). The district is administratively divided into nine divisions, 37 wards and 164 villages. Kilosa District Hospital provides both out- and in-patient services. It has a 150 bed-capacity and acts as a referral for all 73 primary health facilities in the district. On average the hospital outpatient department attends 100 patients per day (Kilosa District Hospital Annual Report, 2006).

\section{Study design and data collection}

This was a cross sectional descriptive study using both quantitative (hospital-based) and qualitative (community-based) research methods. Focus Group Discussions (FGDs) were conducted to adult community members in the catchment area of the District Hospital. The inclusion criteria were parents/guardians who had attended or had their $<5$ year old children attended the hospital at least once within the last 12 months. Two wards out of three in the hospitals catchment area were selected using simple random sampling technique; and from each ward a village was randomly selected. In each selected village a key informant aided in selecting members for FGDs based on the inclusion criteria.

Exit interviews were conducted to patients or guardian/parents of children attendingOPD services using systematic random sampling based on the projected attendances and list of attending patients for the day. A sample size of participants for hospital-based survey was calculated as described by Cochran (1977). Interview guide was used to explore the community perceptions' on interpersonal relationship, technical competence of health workers, physical environment, adequacy of health workers, availability of medicines in the pharmacy and quality of services offered. The interview stopped after the point of saturation was reached. Hospital-based survey used a questionnaire adopted from Haddad et al (1998). Exiting patients were interviewed to seek their opinions on various aspects of health care.

Each FGD had 8-10 participants and in order to facilitate people to discuss openly, men and women were in separate groups. FGDs were conducted in a place where there was no interference from other people. The discussions were held either in the ward conference hall or a classroom. Kiswahili was used in conducting all focus group discussions with the investigator as a facilitator and a trained research assistant as a recorder. Notes were expanded immediately after each FGD and any contradicting or new information were checked and confirmed in the next FGD. On the average, the discussion lasted for 90 minutes.

\section{Data analysis}

The process of data analysis followed thematic framework of analysis as described by Pope et al. (2000). The method involved systematic process of charting and solving material according to the key issues and themes: familiarization of the raw data by reading transcripts, listening to tapes, studying notes in order to list key ideas and recurrent themes; identifying a thematic framework; indexing (coding); charting, and mapping and interpretation using the charts to define concepts. Hospital based data was entered into a computer twice and again checked for consistency by running frequencies of all variables before being analyzed using SPSS version 12.0 software. Likert scale was used to rank the responses. Due to low number of people in the categories, the five point scale was merged into three level scale; very unfavourable and unfavourable becoming "unfavourable", neutral remaining as it is and favourable and very favourable becoming "favourable"

\section{Ethical consideration}

Ethical approval was sought from Kilimanjaro Christian Medical College Research and Ethics Committee. Official permission was obtained from Kilosa District Medical Officer. Informed written consent was sought from each research participant. 


\section{Results}

\section{Exit interviews}

A total of 127 participants were recruited for hospital-based survey of whom majority 90 $(70.9 \%)$ were females. The overall mean age was $32.8 \pm 1.5$ years (range $=18-80$ years). More than 50\% were in the age group 20-40 years. Eighty $(63.0 \%)$ of the participants were married and $68(53.5 \%)$ were peasants. The majority (78.7\%) had primary school education. Seventyone $(55.9 \%)$ of respondents lived within $5 \mathrm{~km}$ from the hospital. Of the 127 respondents, $70.1 \%$ could answer all questions. In general most of them were of favourable opinion on all aspects of hospital care. Waiting time for consultation ranked least as only $55.1 \%$ responded favourably while $29.1 \%$ responded unfavourably. Majority (85.8\%) of participants responded favourably while $9.4 \%$ unfavourably as regards to sufficiency of good clinicians. The majority $(88.8 \%)$ of the responded described the cost of the service as affordable (Table 1).

Table 1: Views of respondents on various aspects of care $(\mathrm{N}=127)$

\begin{tabular}{|c|c|c|c|}
\hline \multirow[t]{2}{*}{ Aspect of care } & \multicolumn{3}{|c|}{ Percentage in category } \\
\hline & unfavourable & neutral & favourable \\
\hline \multicolumn{4}{|l|}{ Health personnel conduct and practices } \\
\hline Show compassion and support patients & 0.8 & 1.6 & 97.6 \\
\hline Show respect for patients & 0.8 & 1.6 & 97.6 \\
\hline Receives patients well & 0.8 & 0 & 99.2 \\
\hline Is honest & 0.8 & 0 & 99.2 \\
\hline Listens to patients adequately & 0.8 & 1.6 & 97.6 \\
\hline Does a good clinical examination & 1.7 & 0 & 98.3 \\
\hline Total & 0.8 & 0.9 & 98.4 \\
\hline \multicolumn{4}{|l|}{ Adequacy of resources and services } \\
\hline Medical equipment is adequate & 1.6 & 0 & 98.4 \\
\hline Rooms are adequate & 3.1 & 0 & 96.9 \\
\hline Waiting for consultation was not too long & 29.1 & 15.7 & 55.1 \\
\hline Sufficient good clinicians & 9.4 & 4.7 & 85.8 \\
\hline Drugs are available all the time & 0 & 4.7 & 95.3 \\
\hline Total & 8.6 & 5.0 & 86.2 \\
\hline \multicolumn{4}{|l|}{ Health care delivery } \\
\hline Clinicians makes a good diagnosis & 0.8 & 0.8 & 98.4 \\
\hline Clinicians prescribe good drugs & 0.8 & 0.8 & 98.4 \\
\hline Quality of drugs is good & 0.8 & 0.8 & 98.4 \\
\hline Treatment is effective for recovery and cure & 0.8 & 0.8 & 98.4 \\
\hline Total & 0.8 & 0.8 & 98.4 \\
\hline \multicolumn{4}{|l|}{ Financial and physical accessibility } \\
\hline Payment arrangement can be made & 3.4 & 1.1 & 95.5 \\
\hline Cost are affordable & 7.9 & 3.4 & 88.4 \\
\hline Drugs can be obtained easily & 0 & 0 & 100 \\
\hline Distance to the health facility is within reach & 6.3 & 0.8 & 92.9 \\
\hline Clinicians allow sufficient time for patients & 3.1 & 0.8 & 96.1 \\
\hline Total & 4.1 & 1.2 & 94.7 \\
\hline
\end{tabular}


Sixty-nine $(54.3 \%)$ of the participants had opinions on what to be done to improve health service delivery at the hospital. Twenty-two $(31.9 \%)$ proposed that there should be adequate health providers, $16(23.2 \%)$ wanted waiting time to be reduced, while $10(14.5 \%)$ wanted clinicians to be available in the consultation rooms all the time of the working day (Table 2). proposed health workers to observe and adhere to ethics and codes of conducts as described by one of the discussants. "Health workers should follow their ethics....."(Male discussant). Another male discussant had the following to say: "....The nurses should be trained on their language and behaviour"

Participants also complained that

Table 2: Respondents opinions on areas of service that require improvement

\begin{tabular}{lll}
\hline Opinion & $\begin{array}{l}\text { No. of respondents } \\
\text { (Total =69) }\end{array}$ & $\mathbf{( \% )}$ \\
\hline Number of health personnel should be enough & 22 & $(31.9)$ \\
Waiting time should be reduced & 16 & $(23.2)$ \\
Clinicians should be available in consultation room & 10 & $(14.5)$ \\
Health workers should show compassion & 9 & $(13.0)$ \\
Services are satisfactory & 9 & $(13.0)$ \\
Drugs should be available all the time & 7 & $(10.2)$ \\
Cleanliness should be improved & 5 & $(7.2)$ \\
First in first out principal should be observed & 4 & $(5.8)$ \\
\hline
\end{tabular}

\section{Focus group discussions}

A total of 36 (female $=18$; male $=18$ ) participants aged 20-68 years participated in the FGDs. Of the discussants, majority $(77.8 \%)$ had primary school education, $7(19.4 \%)$ had secondary or higher education and $(2.8 \%)$ had no formal education. Majority $(88.9 \%)$ were peasants and the remaining $4(11.1 \%)$ had formal employment. A summary of the issues on quality of care raised by focus group discussant is provided in Table 3.

Bad language from health workers was a major concern of many discussants. Most discussants claimed to have faced or witnessed an incident of bad language from a health care provider as described by some discussants: "Language, especially of attendants is not good; they are so harsh. It happened to me recently" (Male discussant). In addition, a female discussant had these to say: "...Some nurses do not have good language. You may find a nurse shouting at a patient instead of educating him" Other discussants reiterated incidents whereby "some doctors use unfriendly and short cut answers"

Across all focus groups discussions complaints on bad language were thrown towards all cadres in the health care system. To improve provider's language discussants some health workers were not responsive to their needs which may not be clinical care but others things including directions as to where a patient should go next, assistance in retrieving information from documents or reassurance. Lack of assistance and poor reception from health workers were some of the prominent complaints: "The laboratory people are insensitive; it takes too long there. They call us by first-names, and several people may have similar names. When you don't hear your name they start shouting at you. ...... One day one old lady brought her grandchild and she could not read the weight of the child from the card. The health worker shouted at her: 'you should have asked her mother at home. I don't have time to read for you!' (Female discussant). A male discussant had these to say: "I went there and the doctor felt I was a nuisance and he said: 'Don't disturb me I am going for tea". It was around 10am. He could have simply said 'please wait I will be right back. I am going for tea'. Describing a similar scenario, another male discussant commented: "The doctor does not pay enough attention to you; before you say your problem he has already prescribed" Another male discussant added: "It is worse when you take a child that can't express itself. The doctor doesn't pay attention to get to know exactly what is wrong with the child" 
Table 3: Summary of findings on quality of care as responses from the FGDs

\begin{tabular}{|c|c|c|}
\hline Issue & Findings & Participants suggestions \\
\hline \multirow[t]{2}{*}{$\begin{array}{l}\text { Inter personal } \\
\text { relationship }\end{array}$} & $\begin{array}{l}\text { Some health workers do not have } \\
\text { good attitude to patients }\end{array}$ & $\begin{array}{l}\text { Health providers should get training on } \\
\text { customer care }\end{array}$ \\
\hline & $\begin{array}{l}\text { Health workers are not responsive } \\
\text { to patients needs }\end{array}$ & $\begin{array}{l}\text { Health providers should show } \\
\text { compassion to patients }\end{array}$ \\
\hline $\begin{array}{l}\text { Availability of health } \\
\text { providers }\end{array}$ & $\begin{array}{l}\text { Health workers are inadequate and } \\
\text { inefficient }\end{array}$ & $\begin{array}{l}\text { Relevant authorities should make } \\
\text { sure the required cadres are available } \\
\text { and supervised and good working } \\
\text { environment is provided }\end{array}$ \\
\hline Inequity in health care & $\begin{array}{l}\text { There is favouritism in care } \\
\text { delivery }\end{array}$ & $\begin{array}{l}\text { 'First in first out' principle should } \\
\text { be observed except for emergency. } \\
\text { Corruption should be fought }\end{array}$ \\
\hline Quality of clinical care & $\begin{array}{l}\text { Quality of clinical care is sometime } \\
\text { not satisfactory }\end{array}$ & $\begin{array}{l}\text { Patients should be examined properly. } \\
\text { Personnel should have refresher courses. } \\
\text { Personnel need to have regular short and } \\
\text { long training }\end{array}$ \\
\hline Availability of drugs & Drugs are not available all the time & $\begin{array}{l}\text { Efforts should be made to see that drugs } \\
\text { are made available all the time }\end{array}$ \\
\hline Financial accessibility & $\begin{array}{l}\text { Cost for health service is } \\
\text { reasonable } \\
\text { CHF is better than on spot } \\
\text { payment }\end{array}$ & $\begin{array}{l}\text { CHF should be made to pay for inpatient } \\
\text { service }\end{array}$ \\
\hline Privacy / confidentiality & $\begin{array}{l}\text { Rooms for consultation do not } \\
\text { offer privacy }\end{array}$ & $\begin{array}{l}\text { Consultation rooms should be } \\
\text { constructed in such a way that other } \\
\text { people can not see or hear what a patient } \\
\text { is doing or saying }\end{array}$ \\
\hline
\end{tabular}

A good interpersonal relationship was also described as a reflection of other services. Discussants stated that if patients are welcomed well with respect and compassion they assume that other services are good too, as testified by one male discussant: “....Doctors and nurses should behave well, show respect, compassion and listen to patients attentively. If they do these everything else will be fine" They went further by comparing private against government health facility services. "Despite the fact that in private clinics they may have to pay more, patients sometimes go there because of the tender care.... In private clinics they listen to you well, they show compassion and you get the right treatment" (Male discussant).

In general most discussants perceived availability of health personnel as inadequate. Discussants were of the opinion that apart from low staffing; the problem of poor service is compounded by their irresponsible behaviours. These behaviours include moving around and gossiping during working hours leading to delays in providing services. One male discussant had these to say: "Sometimes there are so many patients but you find only one clinician in the consultation rooms. A patient goes there in the morning and leaves at $4 \mathrm{pm}$.. .Recently I took a patient there in the morning and we came back at 6 $o^{\prime}$ clock in the evening. The doctor doesn't stay in the office for long enough". Other female discussants added: "It takes too long to collect cards from reception, and again they practice a lot of favouritism. The queue is too long there! Clinicians are few and those available move around too much. When your turn comes you find the Pharmacy is already closed .... Sometimes you may find nurses sitting in Grade II ward or injection room gossiping".

In all focus groups participants had a feeling that apart from low staffing, there is also a problem of poor allocation of duties, such that sometimes there are no staffs to attend patients. This is mainly because clinicians or nurses are given special assignments or are attending seminars/ workshops/ meetings or running special units at the hospital. There was a concern on some of the work given to nurses. Discussants complained that sometimes, nurses would be found spending a lot of time doing cleaning. They were of the opinion that other people should do the cleaning so health providers should concentrate on patients care. A number of male discussants had the following to say: "Clinicians are usually not in their consultation rooms; you may be told that they 
are in a seminar. How come that all of them go to a seminar?... Other clinicians will tell you that they are assigned to a special sections"....." I think a community committee should be set to look at the behaviour of doctors, because most of the time they are not in their offices.... The government should make sure doctors remain in their offices, not just moving around... The authorities should supervise their subordinates properly" They proposed that the hospital management and the government should take measures to see that clinicians are left to perform their professional duties. They also recommended that the government should provide good working conditions to motivate hospital workers.

A number of participants were of the opinion that the inadequacy of health workers was not real. They believed that if health providers worked as hard as required there would be no problems of delays in provision of health service. Moreover, the delay in health care provision was described to affect only certain groups of people and not all. It was shown from virtually all focus groups discussions that the well-to-do and those who have relatives and friends among the health care providers were given priority in the provision of care. One of the male participants had these comments: "One day as I was waiting to see a doctor, there came beautiful ladies and the doctor took them into his consultation room. We had to knock his door may times but the doctor said that they were also patients".... "Another day I asked a doctor to attend my child. He asked me for TShs. 500 before he could attend the child.... In addition, a female discussant had this to add: "Some patients will go to hospital knowing who they are going to meet. The patients will go into a clinician consultation room and get attended, leaving you waiting despite the fact that you were there before them..."

Majority of respondents perceived cost for medical care to be reasonable and affordable. However, most of the time patients would be told to buy medicines from shops despite the fact that their insurance cover is supposed to cater for medical services including medicines. This made patients to incur unnecessary costs which sometimes they can not afford. Unpredictable availability of drugs was raised by majority of participants in all focus groups. Some participants wondered why drugs were not available in the district hospital while they were plenty in shops and private health facilities. They had these to say: "Availability of medicines is a problem, as we are told to buy them .... They should strive to see drugs are available all the time".

Discussants were very positive to the introduction of health insurance schemes. One male discussant had these to say: "Community Health Fund is good. One has to pay TShs. 5,000 and the whole family gets service throughout the year. If you go to Muhombolage (a private dispensary) TShs. 1,000 is only for consultation, still you will have to buy medicines. However, the best quality of care makes us attend to private health facilities!"

There was a general opinion that Community Health Fund (CHF) was better than on spot payment. It was described to be relatively cheap and very useful as described by one of the discussants: "The government decided that we contribute so that we get medicines, now we don't get them! The cost is reasonable except the fact that you don't get medicine at the hospital so you have to spend more for buying drugs from private shops .... Our salaries are deducted every month and we still don't get medicines.... TSh 2,000 is not so much now but for the poor it may be a lot of money. CHF is better because you only have to pay TSh. 5,000 once and your family is treated throughout the year"

When asked whether they would accept an increase in the insurance premium so that medicines are readily made available, majority agreed. "I don't see why they say there are no drugs. If what we contribute is not enough they should increase the premium to as high as TSh. 500-1,000 as living costs are also high nowadays" They went further by requesting that CHF should also cover for inpatients services. Again in one female focus group discussion there was a consensus that there should be an increase in the premium to cover for inpatient care. "If you get admitted your CHF will not work, it is for outpatient services only.... I would suggest that we pay TSh. 10,000 so that CHF members can get inpatients services as well. The current costs are reasonable.

However, a few discussants, were concerned that the very poor in the society may not be able to pay for the service: "If we increase the pay the poor in the village will die" (A female discussant). It was agreed that an exemption mechanism if properly instituted may help the poor. The current unclear guidelines were found to be a constraint in helping the poor as one discussant said: "Elderly people are supposed to be exempted but they are still required to pay. One day I went there and said I didn't have money and I was expelled" (A male old discussant). Another discussant had these to add: "It is not clear who among the elders is entitled to exemption. Things are 
mixed up, and you may find the older is paying while the younger is not"

Lack of equalities was also observed between different types of payment schemes. Discussants complained that those on out of pocket payment mechanism were given less priority as compared to members of $\mathrm{CHF}$ scheme. On the other hand, the later complained to be treated as inferior to members of the National Health Insurance Fund scheme as described by one of the male discussants: "NHIF members are given priority in doctors rooms, CHF members have to wait, they also paid for the service!... There is a problem at the reception, if you don't have CHF card you will be asked to wait while those with cards are being attended"

All focus group discussants indicated that they want good clinical care. They perceived care provided at the hospital to be deficient in various aspects including clinical examination, prescriptions and case management. This problem was perceived to be exacerbated by absence of qualified staff. They were not in favour of being attended by unqualified personnel. Comparing with the old days, discussants had these to say: "in the old days, if you go to see a doctor, they would use a thermometer to check your temperature. This is no longer done. These days, before you finish presenting your problem, the doctor has already prescribed for you. Even stethoscopes are not being used anymore these days....Even medical attendants, who are not trained, have recently started giving injections... I don't see why they should not bring specialists here. I have been suffering from bone problems for 10 years and every time I come to hospital, a clinician would prescribe pain killers. I took an X-Ray picture and he could not interpret"

Complaints were also raised on the deployment of Clinical Officer trainees in the management of patients. Discussants preferred the trainees to work under supervision of qualified personnel. In all FGDs, discussants complained that "Although there are qualified clinicians, sometimes we are treated by trainees alone... Sometimes doctors leave trainees on their own. They give them too much authority. This should not be allowed to continue. They should be supervised" Despite these complaints on clinical care, some of the discussants praised the available health workers for the good service they were providing. One had these to say: "Though we are complaining they are still doing a good job, they deserve praise for that!" Describing areas that were offering reasonably good service, one discussant said: "The X-ray service is usually always available; there is no problem with it. Staff in the X-ray unit offers a good service; even when the service is not available for some reasons they will inform you"

Another issue that was raised by several discussants was about confidentiality and privacy. They claimed that there have been instances where information that was meant to be confidential between provider and patient was disclosed to the public. This problem was thought to be compounded by the improper construction of consultation rooms whereby it was possible for other patients to hear or see another patient in the adjacent consultation room. On the other hand, majority of the participants were of the opinion the problem of breach of confidentiality among health providers was relatively low.

\section{Discussion}

This study describes users' perception of quality of outpatient care in a rural district hospital in Tanzania. Users have pointed out several shortcomings including bad language and unresponsiveness to patients' needs by health workers, inadequacy of health workers, unreliable availability of medicines and favouritism in health care provision. Overall respondents in hospital based study perceived quality of care at the hospital OPD as favourable. This concurs with other studies done in Tanzania (Urassa et al., 2002;) and elsewhere (Haddad et al., 1998a; Schneider \& Palmer, 2002; Baltussen $\& Y e, 2005)$. High favourable opinion on quality of care found from hospital based part of this study may not necessarily reflect a good quality of care. However, this may also be due to the fact that respondents wanted to give socially desirable answers probably because they were preoccupied by their suffering or they felt threatened to respond unfavourably within the hospital environment. This kind of behaviour was reported in a study in South Africa (Schneider \& Palmer, 2002). Like in the study in South Africa, participants in our study became more critical during focus group discussion.

Provider-patients interaction was given critical importance and was perceived to be deficientbecauseofbadlanguage, poorreception, and lack of attention and responsiveness to patients needs. This was in agreement with findings from studies done in elsewhere (Leon, 2003; Kamuzora \& Gilson, 2007). The kind of health care-provider interaction a patient experiences affects compliance to treatment and continuum of care. It is one of the most important issues for clients. It also has a 
profound impact on the ability of the patient to communicate symptoms to his/her provider and on the patient's feelings of being respected or disrespected (Akin \& Hatchnson, 1999; Leonard et al., 2002; Kamuzora \& Gilson, 2007). In this study, community members also felt that it is reassuring that the provider is going to offer good care if he/ she shows respect, compassion and receives patients well. Therefore good provider-patient interaction may be seen as a precursor to reflection of the other aspects of care (Haddad et al. (1998).

The poor interpersonal relationship was described as one of the main reasons that patients would prefer private than public health facilities. Staffs at the former facilities were described to be more compassionate and respectful compared to government facilities. Similarly, in a recent study in China private facilities were hailed for good manners, respect, and attention to patients of their staff (Lim et al., 2004). Often, users seek service from other facilities or experience for comparison when judging quality of care and therefore available alternative place for care may influence how a facility is perceived (Schneider \& Palmer, 2002). In this study, although within the hospital catchment area there is no other hospital; respondents could compare the attitude of staff with those in private dispensaries. Other studies have also documented that users usually bypass the facilities that offer care of less than perceived necessary quality (Leonard et al., 2002; Akin \& Hutchinson, 1999). This may mean extra distance and hence, more cost will be incurred by the client.

Cost of services at the hospital was generally perceived to be reasonable. However, it appears that availability of medicines is the most important factor used to measure the value for money as regards to health care provision. In all focus group discussions, discussants were referring the cost of service in reference to medicine availability. Kamuzora \& Gilson (2007) found that community members are more willing to pay for health service if medicines were available. In this study community members were willing to contribute more so as to make sure medicines are made readily available. Like in this study, other studies have reported that the availability of medicines is the most important aspect of quality of care (Haddad et al., 1998).

Availability of health personnel in the hospital was generally perceived inadequate though there were doubts whether the available staffs were functioning efficiently. People believe that health personnel do not work for the number of hours paid for. In our study, participants noted that the available health workers were in some instances engaged in special health programmes and activities that are not directly related to patients care. Similar findings have been reported in a recent study in Tanzania by Kamuzora \& Gilson (2007). Misuse of providers' time for gossiping and other unproductive activities should not be underrated as it came up very strongly in focus group discussions. It is also supported by a recent report that there is about 65 to $75 \%$ potential for productivity increase by health workers in Tanzania if working time is spent on productive activities and the activities are done efficiently (Mæstad, 2006). Moreover, availability of health professionals has a bearing on the quality of service that is offered and certainly on users' perception as reported from other studies (Smith \& Sanderson, 1992; Haddad et al., 1998; Lomoro et al., 2002; Leon, 2003; Groenewegen et al., 2005; Lim et al., 2004; Manongi et al., 2006; Kamuzora \& Gilson, 2007).

Inequality in accessing timely health care service was also attributed to favouritism among health care providers. Favouritism in Tanzania is also perceived to be linked to bribes (Langseth \& Michael, 1998; Kamuzora \& Gilson, 2007). This calls for policy makers and implementers to have check mechanisms for ensuring equity. Importance of privacy and confidentiality in health care provision was also aired in this study. For patients to be able to give information freely, visual and audio privacy is considered important. After a patient is seen by the provider, information obtained is expected to be kept in confidence. Failure to observe this may cause embarrassment to both patients and providers. Other studies have also reported the importance of privacy and confidentiality (Humayun et al., 2008).

In conclusion, this study has highlighted the importance of users' feedback in health care provision. The findings indicate areas for improvement including removal of poor interpersonal relationships between providers and patients, delays in provision of care, unreliable supply of medicines, favouritism and lack of privacy. Addressing the identified weaknesses will improve quality of care and hence users perception and better health status of the population. Efforts should be put to see that health providers are compassionate and respecting to patients. This may be achieved by incorporating customer care and social skills courses in their training and on job training. The 
hospital administration should pay attention to all sections and address the gaps. This may be realised by strategic allocation of manpower, synchronization of staff number with patients' tides (fluctuations), supportive supervision and improvement of primary health care system and disease prevention. Continued supply of essential medicines should be maintained.

Received 28 May 2009

Revised 24 August 2009

Accepted 7 September 2009

\section{References}

Akin, J.S. \& Hutchinson, P. (1999) Health care facility choice and the phenomenon of bypassing. Health Policy and Planning 14, 135-151.

Baltussen, R. \& Ye, Y. (2006) Quality of care of modern health services as perceived by users and non-users in Burkina Faso. International Journal for Quality in Health Care 18, 30-34.

Groenewegen, P., Kerssens, J., Sixma, H., van der Eijk, I. \& Boerma, W (2005) What is important in evaluating health care quality? An international comparison of user views. BMC Health Services Research $5: 16$

Haddad, S., Fournier, P., Machouf, N. \& Yatara, F. (1998) What does quality mean? Community perception of primary health care services in Guinea. Social Science \& Medicine 47, 381-394.

Haddad, S., Potvin, L., Roberge, D., Pineault, R. \& Remondin, M. (2000) Patient perception of quality following a visit to a doctor in a primary care unit. Family Practice 17, 21-29.

Humayun A., Fatima N., Naqqash, S., Hussain, S., Rasheed, A., Imtiaz, H. \& Iman, S.Z. (2008) Patients' perception and actual practice of informed consent, privacy and confidentiality in general medical outpatient departments of two tertiary care hospitals of Lahore. BMC Medical Ethics 9, 14.

Jung, P., Weising, M. \& Grol, R. (1997) What makes a good general practitioner: do patients and doctors have different views? British Journal of General Practice 47, 805-809.

Kamuzora, P. \& Gilson, L. (2007) Factors influencing implementation of the Community Health Fund in Tanzania. Health Policy and Planning 22, 95-102.
Langseth, P. \& Michael, B. (1998) Are bribes payments in Tanzania "grease" or "grit". Crime, Law and Social Change 29, 2-3.

Leon, M. (2003) Perceptions of Health Care Quality in Central America. International Journal for Quality in Health Care 15, 6771.

Leonard, K.L., Mliga, G.R. \& Haile Mariam, D. (2002) Bypassing Health Centres in Tanzania: Revealed Preferences for Quality. Journal of African Economies 11, 441-471.

Lim, M., Yang, H., Zhang, T., Feng, W. \& Zhou, Z. (2004) Public perceptions of Private health care in Socialist China. Health Affairs 23, 222-234.

Lomoro, A., Ehiri, E., Qian, X. \& Tang, L. (2002) Mothers' perspectives on the quality of postpartum care in Central Shanghai, China. International Journal for Quality of Health Care 14, 393-402.

Mæstad, O. (2006) Human Resources for Health in Tanzania: Challenges, Policy Options and Knowledge Gaps. CMI Report R 2006:3, Bergen, Norway (Available at: $\underline{w w w . c m i}$. no/publications/file/?2175. (Accessed on 28 June 2008).

Manongi, R.N., Marchant, T. \& Bygbjerg, C.I. (2006) Improving motivation among primary care workers in Tanzania: a health worker perspective. Human Resources for Health 4:6.

$\mathrm{MoH}$ (2005) Review of the State of Health in Tanzania 2004. Ministry of Health, Dar es Salaam, pp 21-23.

Øvretveit, J. (1992) Health Service Quality. Oxford: Blackwell Scientific Press.

Schneider, H. \& Palmer, N. (2002) Getting to the truth? Researching user views of primary health care. Health Policy and Planning 17, 32-41.

Smith, J. \& Sanderson, C. (1992) What makes outpatient attendance worthwhile for patients? International Journal for Quality in Health Care 4, 125-132.

Urassa, D., Carlstedt, A., Nystrom, L., Massawe, S. \& Lindmark, G. (2002) Quality assessment of the antenatal program for anaemia in rural Tanzania. International Journal for Quality in Health Care 14, 441448.

WHO (2000) Better Out-Patient Services are the Key to Health Gains for the Poor. World Health Organization, Geneva (WHO/47).

WHO (2004) Quality Improvement in Primary Health Care. World Health Organization, Geneva. 